\title{
Francisco Javier Díez de Revenga, Los poetas del 27: clásicos y modernos, Colección Estudios Críticos, Ediciones Tres Fronteras, Murcia, 2009, 272 pp.
}

El catedrático de Literatura de la Universidad de Murcia, Francisco Javier Díez de Revenga, especialista en el estudio de la generación del 27 internacionalmente reconocido, acaba de publicar en Murcia, en la Colección Estudios Críticos de la Editorial Tres Fronteras, un completo libro sobre los componentes de esta generación, titulado Los poetas del 27, clásicos y modernos ${ }^{1}$.

Se trata en este ensayo de los poetas más importantes de todo el siglo XX, empezando por Federico García Lorca y sus amigos, con los que llevó a cabo muchas aventuras literarias que han tenido una extraordinaria e inusual trascendencia posterior. Lorca nació, como nuestro Premio Nobel de Literatura Vicente Aleixandre y Dámaso Alonso, en 1898. Mayores eran, nacidos en la década de los noventa Pedro Salinas, Jorge Guillén, Gerardo Diego, Emilio Prados (nació en 1899). Los más jóvenes, nacidos ya en el siglo XX, fueron Luis Cernuda, Rafael Alberti y Manuel Altolaguirre, nacido ya en 1905.

Y todos en conjunto han recibido la denominación colectiva tan discutida de "generación del 27 , las antologías... Lo cierto es que surgen como grupo a partir de 1920 en el entorno de Juan Ramón Jiménez, se reúnen en 1927 en la conmemoración del centenario del gran poeta del siglo XVII, muy olvidado en ese momento, Luis de Góngora; todos ellos publican sus primeros poemas en revistas que resultaron efímeras pero que hoy consideramos eternas. Gerardo Diego los reúne por primera vez en su mítica Antología en 1932 y, desde el punto de vista estético, y ese es uno de los signos más poderosos y visibles de su modernidad, logran la imposible fusión entre tradición y vanguardia. Finalmente, se dispersan, tras la muerte de Federico García Lorca, algunos marchan al exilio interior o exterior y lo cierto es que mantienen y crean mundos poéticos originales hasta la senectud. Dámaso Alonso, en 1948, fue el que los denominó "generación poética" y la historia literaria los aglutina como el equipo más coherente y valioso que nuestra literatura ha aportado a la europea.

En relación con Murcia, hay que señalar que todos y cada uno de estos diez poetas publicaron sus primeras composiciones en Murcia, en revistas murcianas. Primero fue en el propio diario La Verdad, en su página literaria, que luego se convertiría en otra de las revistas míticas del momento, el “Suplemento Literario" de La Verdad, desde 1923 a 1926. Un personaje, muy amigo de Juan Ramón Jiménez, el murciano Juan Guerrero Ruiz, dirigía esta página, y a través de Juan Ramón, consiguió que colaboraran todos. A Murcia vino, en 1926 como catedrático de Literatura Española de la Universidad, uno de ellos, Jorge Guillén, que colaboró con Guerrero en el "Suplemento", y en 1927 decidieron independizar la publicación, y crearon Verso y Prosa, que se anunciaba como "Boletín de la Joven Literatura", y fue una de las revistas más valiosas y significativas del momento. En ella colaboraron

\footnotetext{
${ }^{1}$ Francisco Javier Díez de Revenga, Los poetas del 27, clásicos y modernos, Colección Estudios Críticos, Ediciones Tres Fronteras, Murcia, 2009, 272 pp.
} 
todos los poetas de los que estamos hablando, y escritores de Murcia como José Ballester, Andrés Sobejano, Antonio Oliver y hasta la jovencísima Carmen Conde. Como todas las revistas del momento, estaba abierta al mundo del arte, y en ella aparecieron reproducciones de los artistas más valiosos del momento (Picasso, Dalí y tantos otros) y, por supuesto, de los pintores murcianos de esta época: Pedro Flores, Luis Garay, y el aún más joven Ramón Gaya, que apenas tenía 16 años, cuando publica pinturas suyas en Verso y Prosa.

Es interesante la denominación de "clásicos y modernos", que se da en el título del libro. Porque en realidad son contemporáneos nuestros, algunos de ellos han desaparecido hace muy pocos años, ya que llegaron en activo a la senectud. Trajeron a la poesía española la modernidad más absoluta, la renovaron como no se había hecho desde hace siglos y lograron alcanzar una categoría personal como escritores, como poetas, muy alta, lo que los ha convertido en modelos de las generaciones siguientes, cada uno a su manera y cada uno en diferente medida y según la época. Pero lo cierto es que su ejemplo ha influido mucho no solo en las generaciones de poetas siguientes, sino en la formación de muchos españoles que los han leído y los leen constantemente.

Díez de Revenga publicó su primer trabajo sobre esta generación en 1971, justamente un estudio, pionero en aquellos años, sobre la revista Verso y Prosa. Hizo su tesis doctoral sobre la métrica de estos poetas en 1973; en la Academia Alfonso X el Sabio ingresó con un discurso de recepción sobre las revistas murcianas de esta generación. Eso fue en 1975. Ha editado a Gerardo Diego, de quién publicó Poesías completas y Prosas completas, a Jorge Guillén, a Emilio Prados, a Manuel Altolaguirre, a Pedro Salinas en tres o cuatro ocasiones... Luego, ha escrito muchos trabajos y algunos libros sobre ellos: en concreto sobre Guillén, sobre Aleixandre y sobre Gerardo Diego. La cátedra de Universidad la obtuvo con un trabajo original de investigación consistente en un estudio que tuvo mucho éxito ya que obtuvo el Premio Anthropos: Poesía de senectud, donde estudiaba la poesía de ellos, ya ancianos... Incluso estudió la narrativa breve de todos ellos en un volumen que obtuvo el Premio Emilio Alarcos, de la Fundación Príncipe de Asturias, en 2002.

Ha publicado nada menos que cuatro antologías sobre el grupo del 27, una para Alambra, en 1988, otra para Alambra Longman, en 1995, la tercera para Devenir, con el título de Los poetas del 27. Cien poemas, en 2003, y la última, de la que se imprimeron 10.000 ejemplares para la Junta de Andalucía, con motivo del 80 aniversario del 27, en 2007. Ese mismo 2007 publicó Las traducciones del 27. Estudio y antología, en Sevilla, en la Fundación Juan Manuel Lara. En los últimos veinte años publicó numerosos estudios, que se han ido incrementando durante los congresos de los centenarios de todos ellos.

En este libro, Los poetas del 27: clásicos y modernos, se recogen sus "mejores páginas" sobre cada uno de los diez, y en ellas estudió aspectos muy variados de sus mundos poéticos, ya que estudia aspectos menos conocidos de sus universos literarios. Así, de Salinas su poesía del exilio, con su vertiente satírico-moral; de Guillén su enfrentamiento vital a Quevedo; de Gerardo Diego su poética de vanguardia creacionista; de Aleixandre su visión de la utopía y del paraíso; de Lorca, el conflicto 
del poeta y la ciudad; de Dámaso Alonso su innovación, pero también su revolución; de Prados su interpretación de la poesía pura española; de Cernuda, sus comienzos, justamente en las revistas de Murcia; de Alberti sus escarceos con la primera vanguardia; y de Altolaguirre su sentido trágico entre poesía pura y humanización. En total, diez estudios, diez capítulos, diez aportaciones, definitivas sobre estos excelentes poetas españoles el siglo XX.

Concepción Ruiz Abellán 